\section{Commentary: Yes! Size is important when performing aortic valve repair}

\author{
Jessica Forcillo, MD, MSc, MPH, ${ }^{a}$ \\ J. James Edelman, MD, $\mathrm{PhD},{ }^{\mathrm{b}}$ and \\ Vinod H. Thourani, MD $^{\mathrm{c}}$
}

Valve-sparing root replacement or aortic valve (AV) repair techniques are an increasing part of our surgical armamentarium to treat younger patients with aortic root aneurysm with or without concomitant aortic insufficiency (AI). This is an attractive biological option that is more viable in patients who are younger or of child-bearing age. Over the past 2 decades, numerous technical modifications have been introduced to improve the long-term durability of these complex patients. These procedures are technically challenging, and most have recommended that they be performed by experienced surgeons. To date, there remains debate on the most durable and successful surgical technique, and some important questions remain. Should we create neoaortic sinuses (remodeling vs reimplantation)? Which technique is the best to prevent high mechanical stress on the aortic cusps and to achieve a better stabilization of the aortic annulus to prevent recurrent $\mathrm{AI}$ and failure, leading to longer-term durability? In addition, intraoperative complexities of AV repair are numerous: (1) how does a surgeon reduce and stabilize the aortoventricular junction with a spherical Dacron device without preventing root deformation, (2) how does one achieve the perfect coaptation height for all 3 of the aortic leaflets, or (3) how does one match the height of the sinuses in a Dacron graft, which may not coincide with the height of the native aortic valve commissures? ${ }^{1}$ These anatomical and technical

From ${ }^{a}$ Cardiac Surgery Department, Centre Hospitalier de l'Université de Montréal (CHUM), Université de Montréal, Montréal, Québec, Canada; 'Department of Cardiothoracic Surgery and Transplantation, Fiona Stanley Hospital, University of Western Australia, Perth, Australia; and ${ }^{\mathrm{c}}$ Department of Cardiovascular Surgery, Marcus Valve Center, Piedmont Heart Institute, Atlanta, Ga.

Disclosures: The authors reported no conflicts of interest.

The Journal policy requires editors and reviewers to disclose conflicts of interest and to decline handling or reviewing manuscripts for which they may have a conflict of interest. The editors and reviewers of this article have no conflicts of interest.

Received for publication Dec 13, 2020; revisions received Dec 13, 2020; accepted for publication Dec 14, 2020; available ahead of print Dec 25, 2020.

Address for reprints: Vinod H. Thourani, MD, Department of Cardiovascular Surgery, Marcus Valve Center, Piedmont Heart Institute, 95 Collier Rd, Suite 5015, Atlanta, GA 30309 (E-mail: vinod.thourani@piedmont.org).

J Thorac Cardiovasc Surg 2022;164:1078-9

$0022-5223 / \$ 36.00$

Copyright (c) 2020 by The American Association for Thoracic Surgery

https://doi.org/10.1016/j.jtcvs.2020.12.071

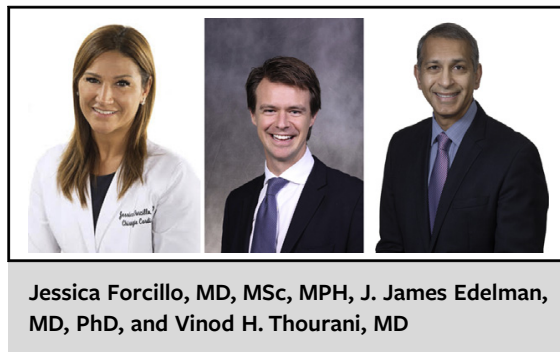

CENTRAL MESSAGE

A preoperative dilated $\mathrm{LV}$ is a risk

for recurrent Al after aortic

valve-preservation surgery.

Whether this is due to technique

or deformation of the aortic-

ventricular junction remains

unclear.

considerations are important, since valve or root alterations could ultimately lead to the failure of the repair.

This eloquent study by Guo and colleagues ${ }^{2}$ assessed the impact of preoperative left ventricular (LV) dimension on the long-term outcomes of AV-preservation surgery. The authors have shown that a greater preoperative left ventricular end-systolic diameter indexed (LVESDi) of $\geq 2 \mathrm{~cm} / \mathrm{m}^{2}$ increases risk of recurrent $>1+\mathrm{AI}$ at 5-year follow-up. This is an extremely well-written article that has now added this new anatomical variable to consider during preoperative planning or the decision to perform that surgery in patients with larger-sized left ventricle. ${ }^{2}$ On their multivariable analysis, preoperative LVESDi $>2.0 \mathrm{~cm} / \mathrm{m}^{2}$ was independently associated with more than a 2 -fold increased risk of recurrent $>1+$ AI. The authors are to be congratulated in now adding this important anatomic preoperative variable for surgeons as they contemplate appropriate therapies.

Since the authors have an extensive and long-standing experience with this patient population, it would be beneficial to understand the extent of postoperative $L V$ remodeling in this population. Do those with a preoperative LVESDi $>2.0 \mathrm{~cm} / \mathrm{m}^{2}$ who have significant remodeling have a lower mid-term recurrence of AI? Furthermore, the relationship of LV remodeling and the deformation of the aortoventricular junction or surgical assembly remains unknown. Differences in LV remodeling in those with a normal versus larger LV will become important as surgeons discuss surgical options with their patients. This is an important consideration 
because significant $\mathrm{LV}$ remodeling after aortic valve replacement, repair, or valve-sparing operations has been demonstrated in different studies. In a study comparing patients who received AV sparing versus replacement with a median follow-up of 46 months (interquartile range, 1778 months), both groups of patients showed a significant reduction in LV end-diastolic and end-systolic volumes. ${ }^{3}$ Similarly, Leshnower and colleagues ${ }^{4}$ showed that the David $\mathrm{V}$ technique produces significant $\mathrm{LV}$ reverse remodeling and LV end-systolic diameter (preoperative $40 \pm 8 \mathrm{~mm}$ vs postoperative $32 \pm 6 \mathrm{~mm}, P<.01)$ and improved ventricular function in patients with chronic severe $\mathrm{AI}$ at $18 \pm 21$ months (interquartile range, 1-89).

In an era in which AV preservation has become increasingly desirable, surgeons are perfecting intraoperative techniques, which has led to excellent short-term outcomes. In this edition of the Journal, Guo and colleagues remind us that it is more than the surgical techniques that are important determinants for long-term success, but also the preoperative size of the LV.

\section{References}

1. David TE. Aortic valve sparing in different aortic valve and aortic root conditions. J Am Coll Cardiol. 2016;68:654-64.

2. Guo MH, Cole E, Fei LYN, Mussani J, Tran D, Glineur D, et al. Preoperative left ventricular end-systolic dimension predicts occurrence of aortic insufficiency following aortic valve-preservation and repair surgery. J Thorac Cardiovasc Surg. 2022;164:1069-76.e2.

3. Regeer MV, Versteegh MI, Klautz RJ, Stijnen T, Schalij MJ, Bax JJ, et al. Aortic valve repair versus replacement for aortic regurgitation: effects on left ventricular remodeling. J Card Surg. 2015;30:13-9.

4. Leshnower BG, Guyton RA, McPherson L, Kilgo PD, Chen EP. Improved left ventricular function and remodeling after the David V for significant aortic insufficiency. Ann Thorac Surg. 2013;96:2090-4. 